\title{
ÜBER EINE GRUPPE HOCHMITTELALTERLICHER PRUNKSPOREN IM SÜDWESTEN DER OSTSEE
}

\author{
ON A GROUP OF RICHLY DECORATED SPURS \\ IN THE SOUTH-WEST OF THE BALTIC SEA
}

\begin{abstract}
A small group of richly decorated spurs has been known for a long time for their characteristic non-ferrous metal covering as well as massive bronze or brass thorn points. Most of them have been found in in the states of Hamburg and Schleswig-Holstein. They are so similar that they could have been manufactured, if not in the same workshop, at least in the same region. The embossed metal sheath, reminiscent of the Late Slavic technology of sheath fittings, could indicate a the Slavic craft tradition. The latest find from a deserted village of Kastaven near Sähle, Oberhavel district in northern Brandenburg, sheds new light on this group of objects. The Kastaven spur has been found in the central area of the settlement which existed between the early $13^{\text {th }}$ and the $15^{\text {th }}$ centuries, in the vicinity of ruins of a church or a churchyard. The spur was probably lost at the village foundation phase, in the early $13^{\text {th }}$ century. This context is of importance to the disputed chronology of the entire spur group, dated back to the late $12^{\text {th }}$ and the early $13^{\text {th }}$ centuries. The finds in Hamburg, Holstein, Eastern Mecklenburg and Northern Brandenburg indicate contacts between the élites in the southwest of the Baltic, related to migrations of petty nobility within the German Eastern Settlement or a communication network of the Slavic Leaders in the Abodrite/Mecklenburg cultural area.
\end{abstract}

Keywords: Riding spurs, Middle Ages, deserted village, Slavic-German contacts, Northern Germany.

\section{EINLEITUNG}

Unter den mittelalterlichen Reitersporen des slawisch-deutschen Kontaktgebietes im Südwesten der Ostsee tritt eine kleine Gruppe von Kugelstachelsporen hervor, die sich durch buntmetallverkleidete Dornstangen und Schenkel sowie massiv gegossene, noppenbesetzte Dornspitzen auszeichnen. Sie sind einander so ähnlich, dass Werkstattgleichheit vermutet wurde. Ihre aufwändige Gestaltung mit gepunztem oder pressmodelverziertem Blech, das in einem Falle durch Vergoldung vere-

* ORCID: 0000-0001-9616-0620; Ernst-Moritz-Arndt-Universität Greifswald, Historisches Institut, Domstraße 9a, D-17489 Greifswald, e-mail: Felix.Biermann@uni-greifswald.de. 
delt wurde, lässt eine Klassifizierung als Prunksporen zu, so dass man sie als Kennzeichen für einen hohen sozialen Status auffassen kann; die Reitutensilien wurden sogar als Nachahmung von Sporen des Hochadels betrachtet, wie sie das Speyerer Grab des salischen Kaisers Heinrichs V. († 1125) enthielt. Aufgrund ihrer Punz- oder Pressblechverzierung, die an die bekannten spätslawischen Messerscheidenbeschläge des 11./12. Jahrhunderts erinnert, gelten sie als Produktion slawischer Handwerker.

Die geringe Zahl dieser Sporen (Abb. 1), ihre zum Teil ungesicherten Fundzusammenhänge und ihr durchweg fragmentarischer Zustand - stets fehlen die Bügelenden - erschweren die nähere Beurteilung der Stücke. Insbesondere ihre chronologische Einordung ist nicht ganz leicht, zumal sie typologisch ältere und jüngere Elemente vereinen: Dorn und Bügel sind in der Seitenansicht ganz oder nahezu gerade, was für hochmittelalterliche Sporen charakteristisch ist, während die kugelförmige Dornverdickung bereits in das späte Mittelalter verweist. Der Neufund eines Sporns dieser Art von der Dorfwüstung Kastaven bei Sähle in der nordwestlichen Uckermark (Gem. Himmelpfort, Lkr. Oberhavel, Land Brandenburg) gibt Anlass, sich dieser Variante von Sporen erneut zu widmen.

\section{DER SPORN VON KASTAVEN}

\subsection{Der historische Kontext des mittelalterlichen Dorfes}

Im äußersten Norden Brandenburgs, zugleich am Nordwestrand der Uckermark, liegt auf halbem Wege zwischen Lychen und Fürstenberg eine Nordost-Südwest-orientierte Seenkette - der Kleine, der Große und der Obere Kastavensee. Die Gewässer erinnern mit ihren Namen an das mittelalterliche, heute wüste Dorf Kastaven oder Kastavel, das sich südöstlich des Großen Kastavensees befand. Dort zeugen noch heute die mitten im Wald gelegene Kirchenruine bzw. die Mauern des Kirchhofs von dem untergegangenen Dorf (Abb. 2).

Kastaven trägt zwar einen Namen mit slawischer Wurzel (Greule 2014, S. 264, mit weiterer Literatur) und liegt im alten Siedlungsgebiet der Rěčane oder Retschanen (Marschalleck 1937, S. 15; Herrmann 1968, S. 28; Enders 1992, S. 21 f., 24), gehörte nach unserem Kenntnisstand aber zu den Dörfern, die erst beim Landesausbau im Zuge der deutschen Ostsiedlung entstanden. Die karge, wald- und seenreiche Himmelpforter oder Lychener Heide war in der Slawenzeit eher dünn besiedelt (vgl. Herrmann 1968, Beilage Abb. 1; Biermann, Kersting 2017, S. 107, Abb. 6) und auch für die Neusiedler nicht allzu attraktiv (vgl. Bergstedt 2002, 27 f.). Obgleich das urkundlich als Riaciani überlieferte Gebiet wohl schon in der zweiten Hälfte des 12. Jahrhunderts unter die Herrschaft der askanischen Markgrafen von Brandenburg geraten war (Enders 1992, S. 40 f.), erfolgte deutscher Landesausbau kaum vor dem frühen 13. Jahrhundert. An dessen Organisation könnten 


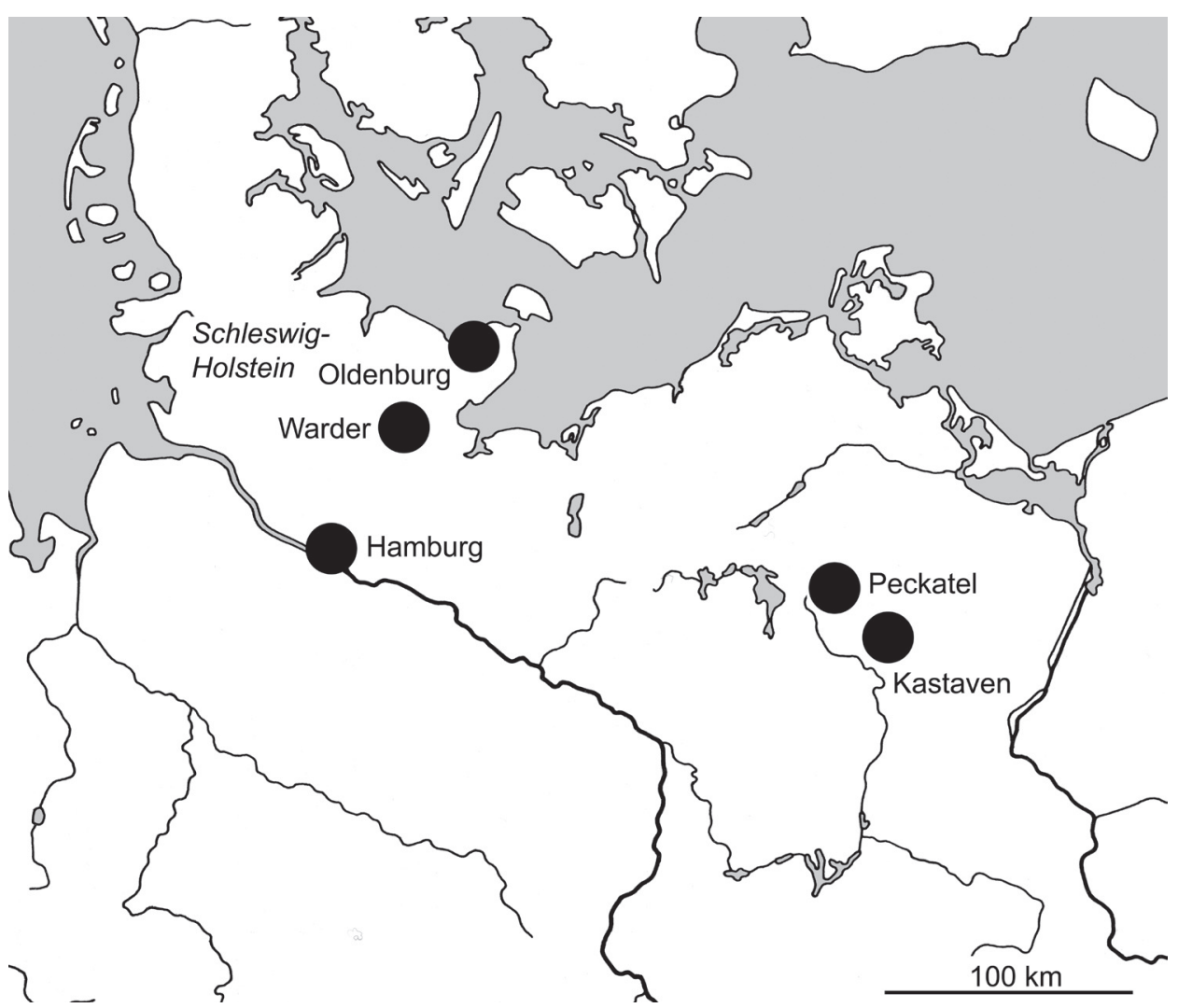

Abb. 1. Die Fundorte der im Text besprochenen Kugelstachelsporen mit Buntmetallverkleidung (Kartierung Verfasser)

sich in diesem Grenzraum neben den Brandenburger Markgrafen auch mecklenburgische und pommersche Fürsten bzw. deren Ministerialen beteiligt haben (vgl. Bergstedt 2002, S. 30), doch gibt es dazu keine schriftlichen Quellen. Einen allgemeinen Aufschwung der Region bewirkte sicherlich das Stadtrecht, das die Markgrafen 1248 an Lychen verliehen (Enders 1992, S. 73 f.; Heinrich 1995, S. 175 f.). Dort hatte bereits eine spätslawische Inselburg bestanden (Marschalleck 1937, S. 17; Herrmann 1968, S. 280). Bei der askanischen Landesteilung 1258 kam das Lychener Land zur ottonischen Linie, ging 1317 aber an das Herzogtum Mecklenburg-Werle über, bevor es 1440 wieder an Brandenburg gelangte (Enders 1992, S. 43, 74; Lange 2010, S. 612 f.).

1299 wird Kastaven erstmals als Carstauel in der terra Lychen erwähnt, als es zu der vom Brandenburger Markgrafen Albrecht III. († 1300) gewährten Gründungsausstattung des $4 \mathrm{~km}$ südlich entstehenden Klosters Himmelpfort gehörte. Damals existierte das Dorf offensichtlich schon, und zwar neben einer später eben- 


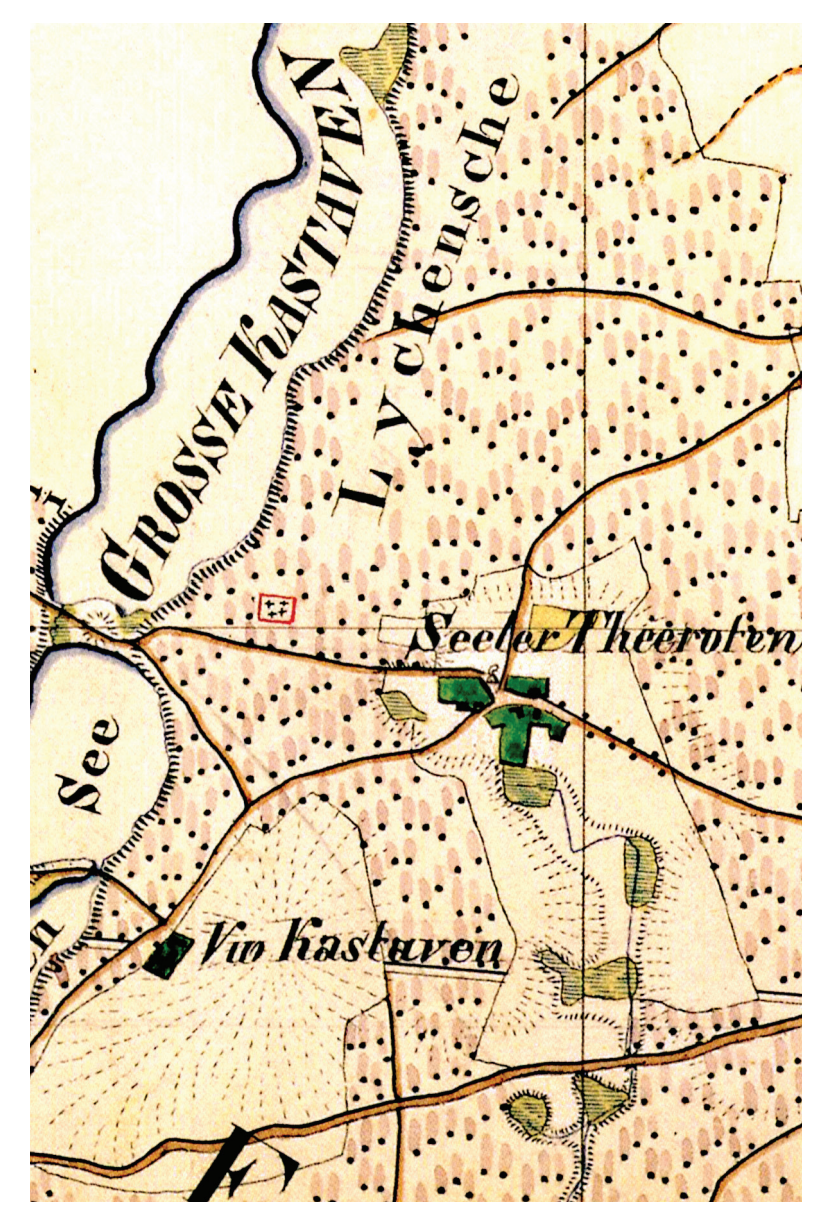

Abb. 2. Der Kirchhof von Kastaven (rotes Viereck mit Kreuzsymbolen) zwischen Seeler Theerofen (Sähle) und Großem Kastavensee, Preußisches Quadratmeilenblatt (Urmesstischblatt) Nr. 2745 von 1825 (Ausschnitt)

falls aufgelassenen Siedlung Klein Kastaven, die bereits 1286 von demselben Markgrafen an die mecklenburgische Johanniterkomturei Mirow geschenkt worden war; Klein Kastaven lag wohl jenseits des Großen Kastavensees auf heutiger Gemarkung Wokuhl-Dabelow (Lkr. Mecklenburgische Seenplatte). Dort befand sich zeitweise auch ein weiterer Komturshof der Johanniter, im heute wüsten Gardow (vgl. Lisch 1844, S. 41 f.; Enders 1986, S. 489). Es läge daher nahe, dass unser Kastaven ursprünglich Groß Kastaven geheißen hat (vgl. Bergstedt 2002, S. 157). 1342 war Kastaven Kirchdorf. Von der Ersterwähnung an bis zur Aufhebung der Abtei Himmelpfort im Jahre 1551 befand es sich in zisterziensischem Besitz. In den bewegten Jahrzehnten nach 1400 war der an der Grenze gelegene Ort Ziel von 


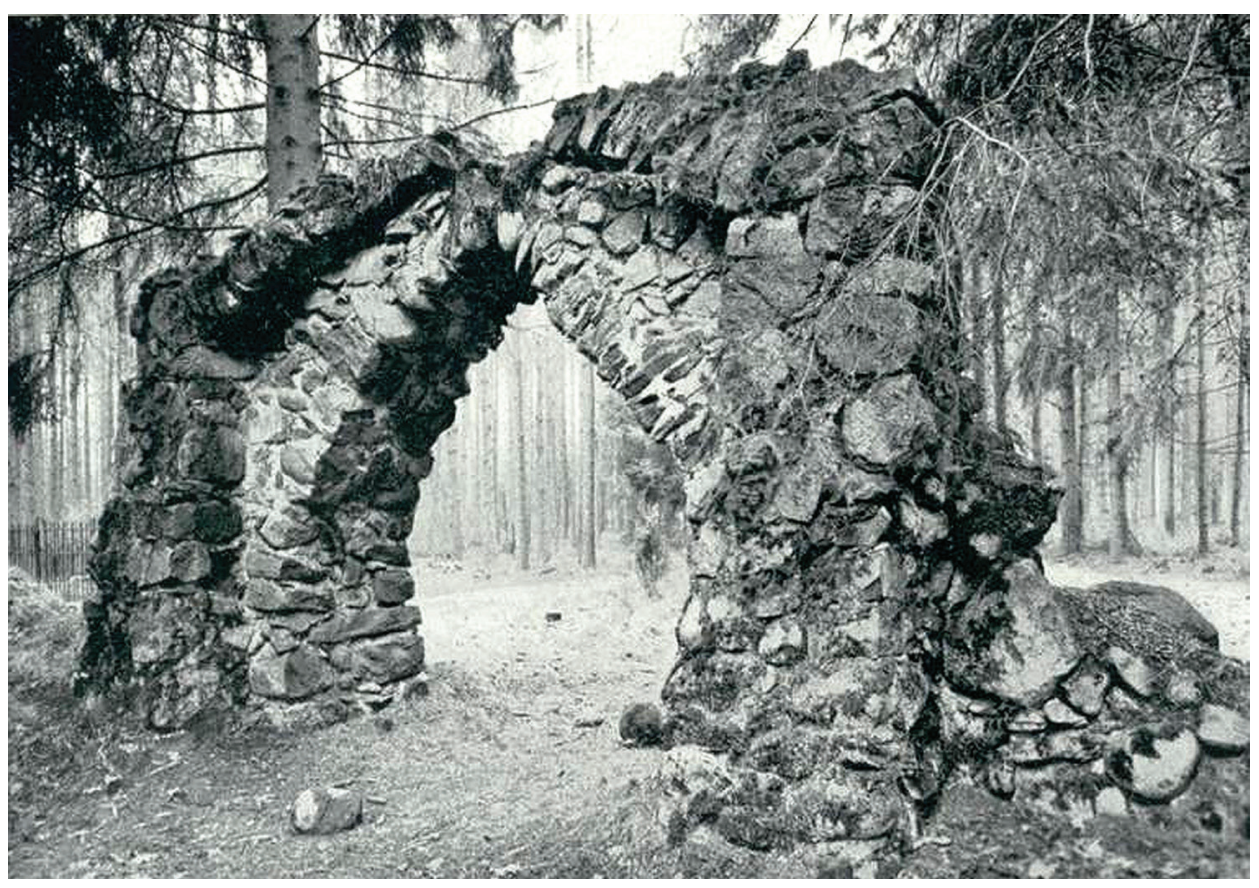

Abb. 3. Die Torruine von Kastaven, Ansicht von der Innenseite in den 1930er Jahren (nach Jerchel 1937, S. 41, Abb. 29)

Überfällen räuberischer Adeliger. Dies mag mit zur Aufgabe des Dorfes geführt haben, die wohl vor der Mitte des 15. Jahrhunderts erfolgte. 1574 ist nur noch vom Kastavener Feld die Rede. Auf der wüsten Gemarkung entstanden später ein Vorwerk und ein Teerofen, der heutige Wohnplatz Sähle $700 \mathrm{~m}$ westlich der Dorfstelle, sowie das Forsthaus Kastaven, das sich $1 \mathrm{~km}$ südlich derselben befin$\operatorname{det}^{1}$.

\subsection{Geländerelikte und ältere archäologische Funde}

Die Lage des Dorfes wird durch eine Kirchenruine markiert, wie sie in etlichen Fällen an die während der großen spätmittelalterlichen Agrarkrise untergegangenen Dörfer der Uckermark erinnern. ${ }^{2}$ Sie wird 1742 als „Alte Kirche“ genannt (Enders 1986, 489). Genau genommen sind heute aber nur noch die Relikte des Kirchhofs

1 Zur Geschichte von Kastaven vgl. Schmidt 1930, S. 27; 1937, S. 25, 30; Sorg 1936, S. 64; Jerchel 1937, 104; Enders 1986, S. 488 ff.; 1992, S. 128; Bergstedt 2002, S. 157 f.; Lange 2010, S. $612 \mathrm{ff}$.

2 Vgl. Schmidt 1930; Jerchel 1937, S. 20; Enders 1992, S. 128; 2003. 


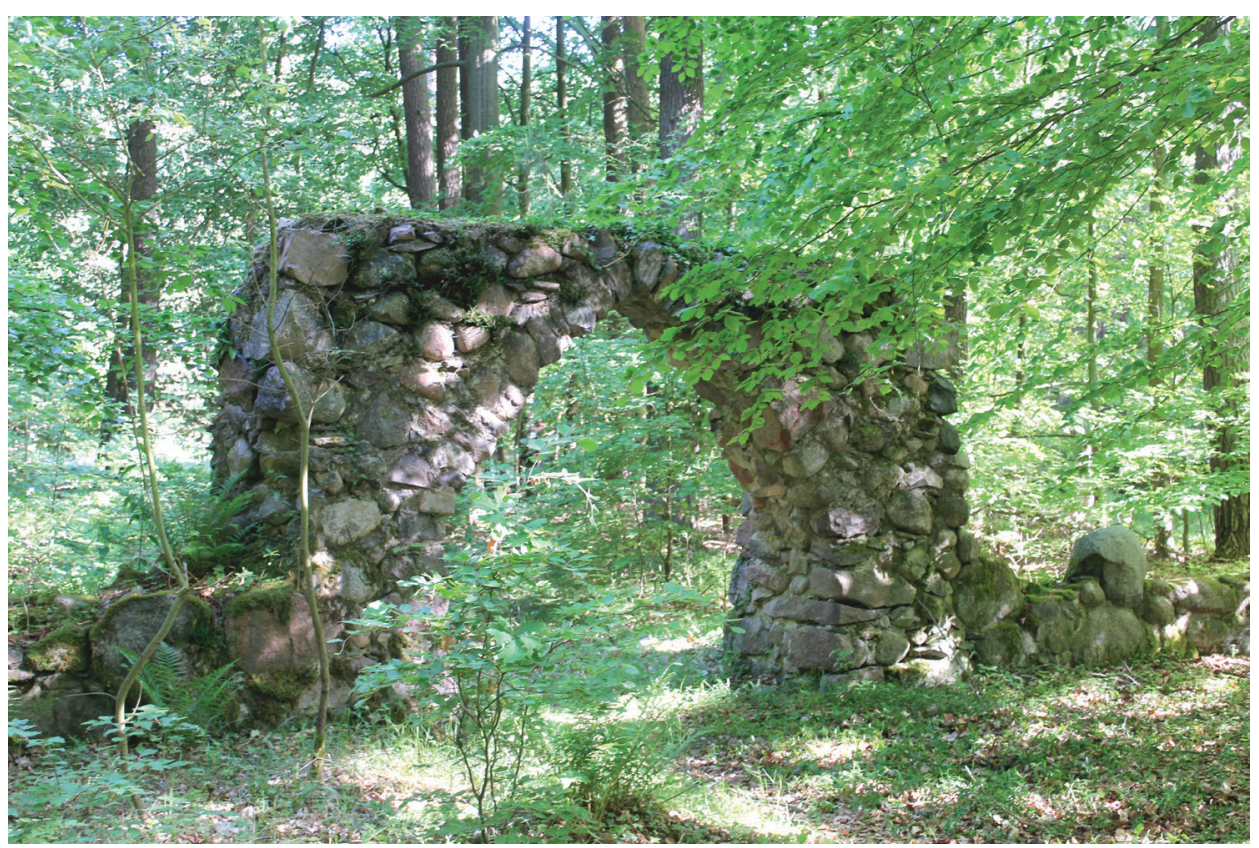

Abb. 4. Dasselbe Tor von der Außenseite, 2017 (Foto Verfasser)

sichtbar: Eine Feldsteinmauer von bis zu $1 \mathrm{~m}$ Höhe bildet ein unregelmäßiges Fünfeck von $50 \times 60 \mathrm{~m}$ Fläche, in dessen Westen, nahe der nördlichen Ecke, ein Tor mit gotischem Spitzbogen aufragt. Das aus vermörteltem Feldstein aufgeführte, offensichtlich im 19. oder frühen 20. Jahrhundert restaurierte Bauwerk hat gut $1 \mathrm{~m}$ Mauerstärke, und auf der Innenseite ist einseitig das Loch für einen Verschlussbalken erhalten (Abb. 3-6). Das könnte dazu verleiten, in diesem Tor den Rest des Westportals der ansonsten niedergelegten Kirche zu sehen. So vermutete es R. Schmidt (1930, S. 26 f., Abb. 14, 15), der ausweislich der von ihm beigebrachten Fotos noch etwas umfangreichere Mauertrümmer antraf. Das östlich an das Gemäuer anschließende Geländerelief gibt aber keine Hinweise auf einen Kirchengrundriss, und spätere Restaurierungen am Torbogen haben etwaige Baufugen verwischt. Es ist wohl wahrscheinlicher, dass es sich bei der Ruine von Anfang an um den Eingang des Kirchhofs handelte, der auch Wehrfunktionen innegehabt haben mag - als Rückzugsort für die bäuerliche Gemeinde bei den oben angesprochenen Überfällen. Das Gotteshaus hätte sich dann zentraler innerhalb des Mauerrings erhoben. Das heute sichtbare Tor und die Umfassungsmauer sind kaum näher datierbar, könnten im Kern aber durchaus in die Zeit des Dorfes zurückreichen (vgl. Schmidt 1930; Jerchel 1937, S. 41, 104, Abb. 29; Enders 1986, S. 490). Vereinzelt umherliegende Grabsteinfragmente und eine erhaltene Grabgruppe bele- 


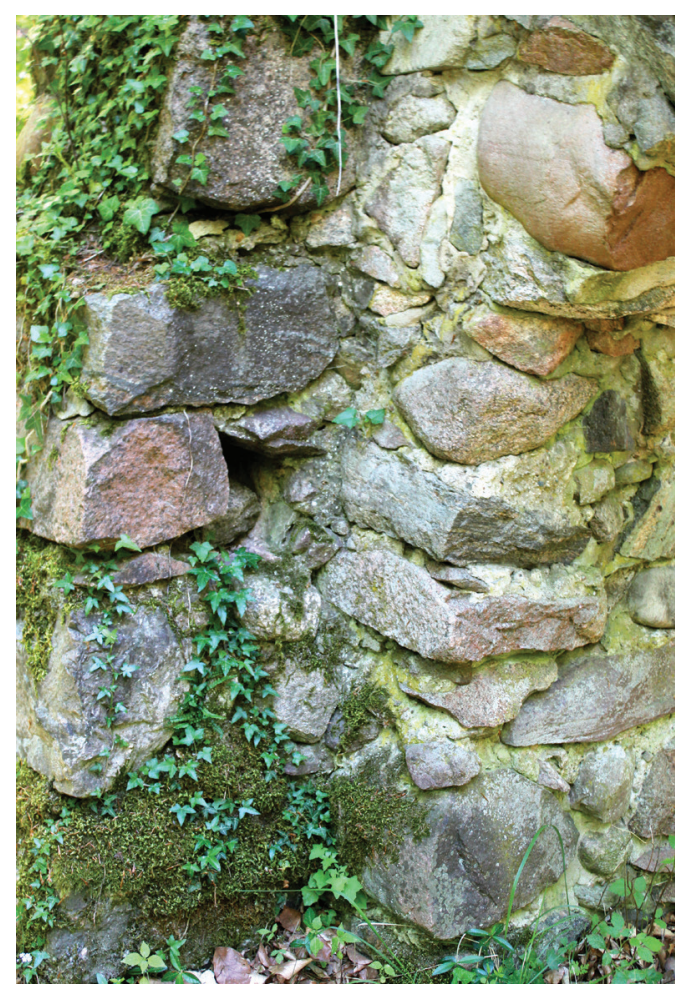

Abb. 5. Aussparung für einen Querbalken auf der Innenseite des Tors (Foto Verfasser)

gen neuzeitliche Bestattungen inner- und außerhalb des Feldsteingevierts, anscheinend bis ins Jahr 1880 (Schmidt 1930, S. 27).

Abgesehen von diesem Kirchhof - „dem unheimlichen Friedhof und den Resten der Wüsten Kirche" (Schmidt 1937, S. 30) - erinnert im dichten Wald oberhalb des Kastavensees nichts mehr an die Siedlung, deren Gestalt und Ausdehnung somit unbekannt sind. Das seit dem 18. Jahrhundert kartographisch dokumentierte und bis heute vorhandene Wegenetz sowie der Umstand, dass unfern des Kirchhofs ein Geländerücken den Übergang des Weges von Lychen nach Dabelow zwischen den Kastavenseen ermöglicht (Abb. 2), könnte für eine West-Ost-Ausrichtung der Siedlung sprechen. Die wenigen archäologischen Informationen zu dem gesetzlich geschützten Bodendenkmal ${ }^{3}$ helfen in der Frage nicht weiter: Aktenkundig ist eine „mittlere Menge recht kleiner frühdeutscher Scherben der harten Grauware mit

${ }^{3}$ Nach alter Gemarkungsaufteilung ist der heute auf Gemarkung Himmelpfort liegende Fundplatz noch Neuthymen zugeordnet: Ortsakten des Brandenburgischen Landesamtes für Denkmalpflege und Archäologischen Landesmuseums (Zossen-Wünsdorf [BLDAM]), Bodendenkmalnummer 70421, Neuthymen Fpl. 6. 
Henkeln und Hinweisen auf Kugelbodenware" sowie ein möglicherweise slawisches Keramikfragment, die im Sommer 1989 bei Aufforstungsarbeiten ans Tageslicht kamen. Der Forstpflug hatte auch „Fundamentreste und Herdstellen“ sowie die Relikte von fünf Hausstellen erfasst, doch erfolgte damals keine genaue Lagezuordnung ${ }^{4}$. In Reihen angeordnete Gruppen rechteckiger Gruben südwestlich und östlich des Kirchhofs gehen auf ein Waldlager der Roten Armee zurück, das 1945 hier bestanden hatte ${ }^{5}$.

\subsection{Der Fund des Sporns}

Auf dieser Wüstung fanden im Mai und Juni 2017 amtliche Metalldetektorsurveys unter Leitung des Verfassers statt ${ }^{6}$. Die Maßnahme erfolgte im Rahmen eines Prospektionsprogramms auf mittelalterlichen Dorfwüstungen Brandenburgs, die Erkenntnisse zu diesen Siedlungen erzielen und zugleich illegalen Aktivitäten entgegenwirken sollen. Das reiht sich in die seit einigen Jahren verstärkte Einbindung ehrenamtlicher Sondengänger in Bodendenkmalpflege und Forschung ein (vgl. Kersting 2015; ders., Petzel 2015; Biermann 2017). Bei der Suchaktion wurden der Kirchhof und seine Umgebung intensiv und großflächig prospektiert. Abgesehen von einigen möglicherweise mittelalterlichen Nägeln und Blechen, etwas blaugrauer Keramik - darunter ein gekehltes Bandhenkelfragment - sowie verschiedenen rezenten Dingen, die teilweise mit dem sowjetischen Militärlager in Verbindung stehen (etwa Patronenhülsen, eine Taschenuhr, ein eingegrabener, metallbeschlagener Holzbottich u. Ä.), wurden dabei kaum nennenswerte Funde gemacht; vielleicht kam die Prospektion an dem einsamen, allgemein bekannten Bodendenkmal, bei dem illegale Sondenaktivitäten schwer zu verhindern sind, bereits zu spät. Es gab aber eine Ausnahme, und sie ist Gegenstand dieses Aufsatzes: ein bemerkenswerter Reitersporn als Vertreter der eingangs umrissenen Formengruppe. Er ruhte wenig östlich der Nordostecke der Kirchhofsmauer gut $15 \mathrm{~cm}$ tief im Waldboden. Hier gibt es einen Mauerdurchbruch nach Osten, bei dem es sich um einen zweiten, wohl ebenfalls alten Eingang zum Friedhof handelt (vgl. Jerchel 1937, S. 104).

\footnotetext{
1989.

${ }^{4}$ Ortsakten des BLDAM, Fundmeldung M. Bußejahn, Dr. U. Schoknecht vom 29. September

${ }^{5}$ Neuthymen Fpl. 5; vgl. zu diesen Lagern, deren Relikte in vielen Wäldern Brandenburgs erhalten sind, Kersting 2016.

${ }^{6}$ Hauptmaßnahme am 27.05.2017, danach noch Nachprospektionen; an der Kooperation der Ernst-Moritz-Arndt-Universität Greifswald (Historisches Institut) mit dem BLDAM beteiligten sich dankenswerterweise O. Blum M. A., M. Fenner und D. Hennicke (Berlin), L. Heiden (Fergitz), A. Kassube (Kuhz), L. Pahl (Finsterwalde), F. Slawinski (Frankfurt/O.) und S. Wolter (Brandenburg/Havel). Für Hilfe und Unterstützung ist Dr. Th. Kersting und Dr. S. Schwarzländer (Zossen-Wünsdorf) sowie Dr. K. Frey (Prenzlau), für die Genehmigung der Maßnahme dem Landesbetrieb Forst Brandenburg (Fürstenberg-Steinförde, Neuendorf) sehr zu danken. Das hier vorgestellte Stück fand S. Wolter.
} 


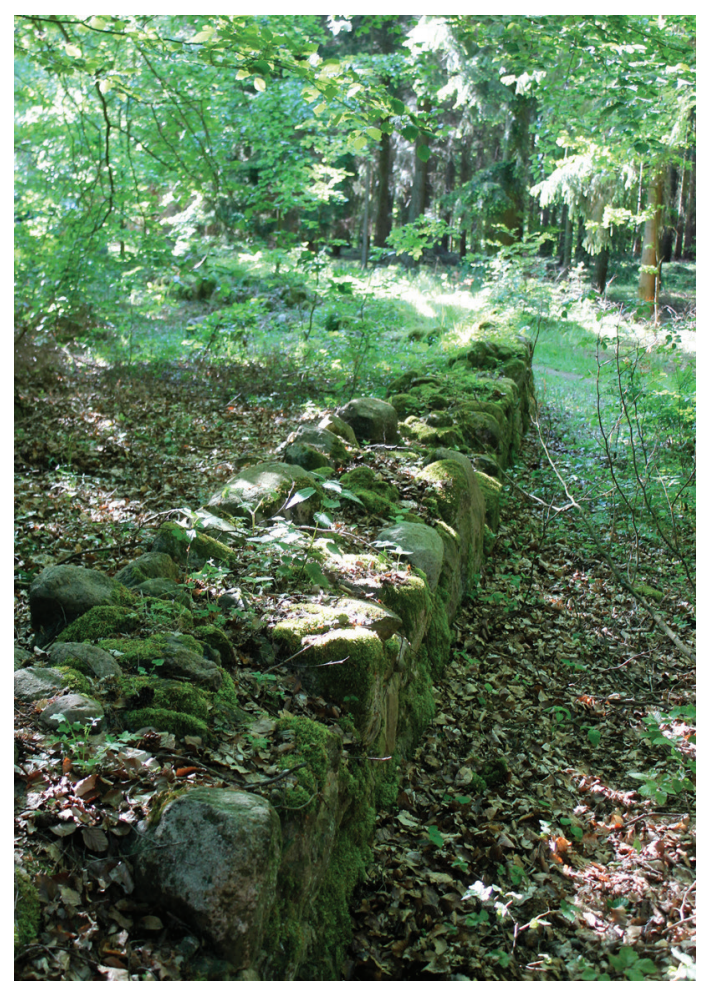

Abb. 6 Die Kirchhofsmauer (Foto Verfasser)

Das Stück lag außerhalb der Umfriedung vermutlich in einem ehemaligen Wege- oder Angerbereich. Da nichts auf die Zugehörigkeit zu einem Grab hinweist, dürfte es sich um einen Siedlungs- bzw. Verlustfund handeln. Der Sporn dürfte wenigstens einige Jahrzehnte älter sein als das heute sichtbare Gemäuer. Dieses nimmt vermutlich aber auf einen Vorgänger, die erste Kirche am Orte, Bezug, denn bei dörflichen Sakralbauten in Brandenburg besteht oft von Anfang an Platzkontinuität (vgl. z. B. Agthe 2017, S. 77-108). So entspricht der Fundplatz des Reitutensils wohl einem zentralen Punkt der Kastavener Siedlungstopographie.

\subsection{Fundbeschreibung}

Der Kugelstachelsporn (Abb. 7-9) ist fragmentarisch erhalten: Ein Schenkel fehlt, das Bügelende am erhaltenen Schenkel ist abgebrochen, das ganze Stück stark korrodiert. Die Gesamthöhe beträgt $12,8 \mathrm{~cm}$, wovon $4,5 \mathrm{~cm}$ auf den Stachel und $8,3 \mathrm{~cm}$ auf den Bügel entfallen. Der erhaltene Schenkel ist geschwungen und 


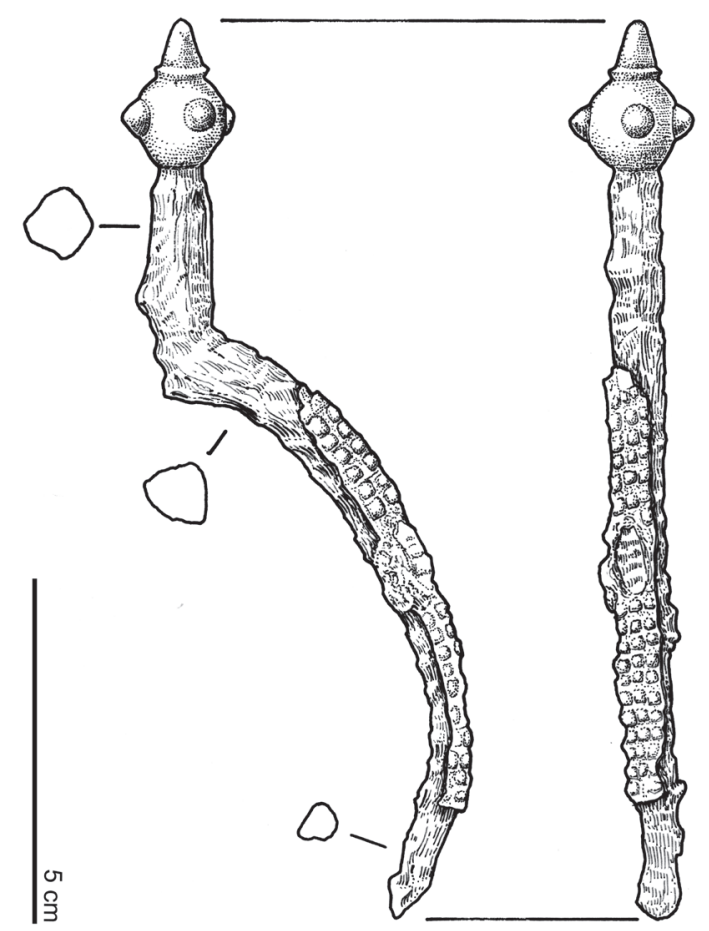

Abb. 7 Kastaven, Sporn (Zeichnung O. Blum, Verfasser)

im Querschnitt dreikantig, die Dornstange ungefähr vierkantig (Durchmesser je ca. $0,7 \mathrm{~cm}$ ). In der Seitenansicht ist der Sporn gerade. Herausragend sind die Reste der Buntmetallverkleidung (wohl Messing) auf dem Eisenkörper. Die Dornspitze ziert ein - vermutlich im Überfangguss aufgebrachter - kugelförmiger Aufsatz (Durchmesser 1,1 cm), aus dem die durch einen ringförmigen Wulst profilierte, deutlich abgesetzte, sachte auslaufende Spitze (Länge 0,8 cm) hervorgeht. Vier rundlich-warzenförmige Applikationen sind mittig an den Seiten der Kugel angebracht. Diese Knubben dürften wie auch die Dornspitze eher eingezapft und aufgelötet als zusammen mit dem Kugelkörper gegossen worden sein. Der erhaltene Schenkel ist ebenfalls buntmetallverziert: Über etwa $6,5 \mathrm{~cm}$ Länge ist eine aus dünnem Buntmetallblech auf den Außenseiten applizierte Verkleidung erhalten, die flächig mit leicht abgerundeten Rechteckbuckeln verziert ist. Diese formieren sich längs und quer zu Reihen. Die Dekoration ist wohl nicht durch Punzierung von der Rückseite her, sondern durch Pressung über einem Model hergestellt worden; anders ist die regelmäßig gelungene Ausprägung kaum erklärbar.

Während die Dornspitze massiv gegossen ist, ist das Pressblech sehr dünn und daher bereits weitgehend abgefallen. Sicherlich verkleidete es ursprünglich auch 


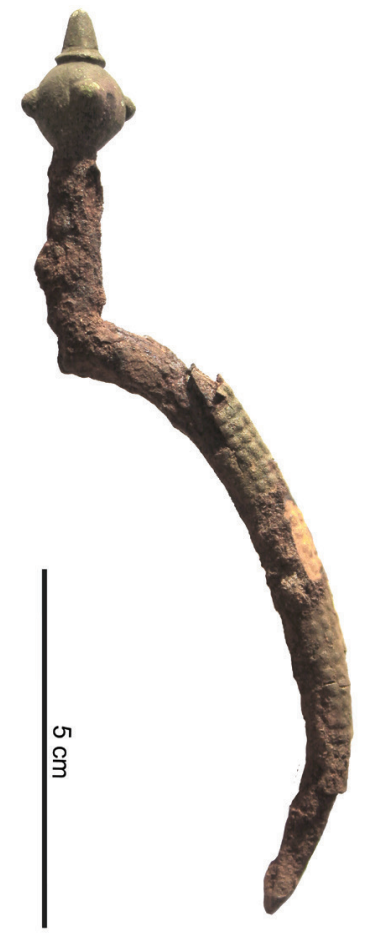

Abb. 8. Kastaven, Sporn (Foto Verfasser)

die Dornstange und den nicht erhaltenen zweiten Bügelschenkel. Dies legt das Erscheinungsbild der noch zu besprechenden Vergleichsstücke nahe. Das Reitutensil entspricht nach seinen formalen Merkmalen der Variante II.1 nach Z. Hilczerówna (1956, S. 34 ff., Taf. III) bzw. der Form AId bzw. A?d nach N. Goßler (1998, S. 517).

\section{VERGLEICHE}

Der Kastavener Fund bestätigt eine kleine Gruppe von eisernen Prunksporen, die sich gleichfalls durch buntmetallverkleidete Schenkel, Dornstangen und -spitzen in Kugelform auszeichnen, und deren Verbreitungsschwerpunkt in Nordelbien liegt. Seit längerer Zeit sind vier Parallelen bekannt (Abb. 10, 11). I. Gabriel zeigt eine Entsprechung aus einer mittelalterlichen Siedlungsschicht der wagrischen Hauptburg Oldenburg (Kr. Ostholstein) (Abb. 10.1). Die olivenförmige Stachelkugel mit vier Noppen ist aus Buntmetall (Messing), ebenso wie die flächig mit Buckelreihen verzierten Verkleidungen von Schenkeln und langer Dornstange. Die kleinen Auf- 

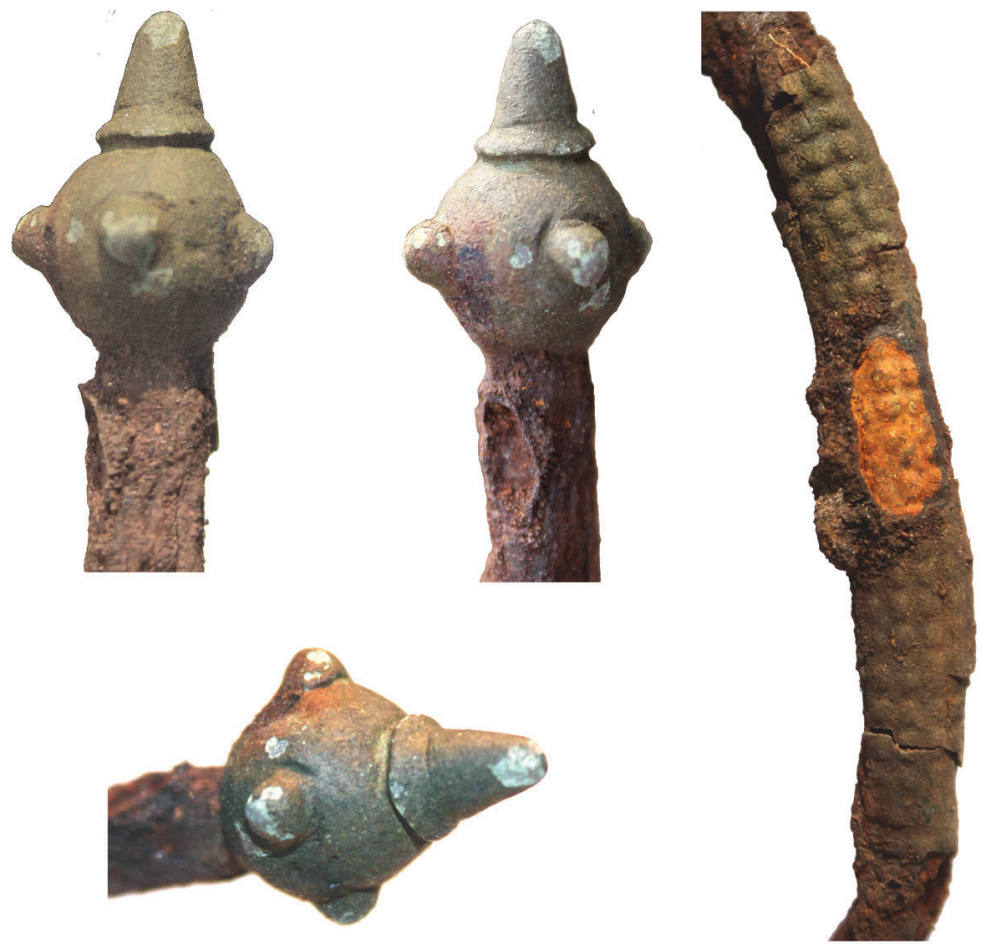

Abb. 9. Detailansichten von Dornspitze und Buntmetallblechverkleidung des Kastavener Sporns (Fotos Verfasser)

wölbungen fallen etwas rundlicher aus als beim Kastavener Exemplar; tatsächlich hebt sich der Neufund durch die kantigere Ausprägung des Flächendekors von allen Vergleichstïcken ab. Die Gesamthöhe des Oldenburger Fragments beträgt 9,3 cm . Das Stück, das I. Gabriel und T. Kempke (1991, S. 145) als „Prunksporn“ „zu den Besonderheiten" des großen Oldenburger Fundspektrums rechnen, fand sich an der "Grenze zwischen Mittelalterschicht und slawischer Schlussschicht" (Gabriel 1984, S. 150). Das entspräche einer Datierung um 1150 oder in der zweiten Hälfte des 12. Jahrhunderts (vgl. Gabriel, Kempke 1991, S. 148, Abb. 27).

Ein weiteres Seitenstück liegt von Warder (Kr. Segeberg) ebenfalls in Holstein vor, und zwar aus der Vorburg der bekannten, vorwiegend spätslawischen Inselburg (vgl. Struve 1981, S. 84-88). In einer Siedlungsschicht, die neben slawischer Keramik braungraue Kugeltopfware der Zeit um 1200 bzw. des frühen 13. Jahrhunderts enthielt, fand sich ein Spornfragment von 7,8 cm Höhe, dessen Blechverkleidungen (wiederum im langen Dornstangen- und Schenkelbereich) flächig perlpunzverziert

${ }^{7}$ Gabriel 1984, S. 129 f., Abb. 42.43; vgl. auch Struve 1985, S. 178, Abb. 57.3; Gabriel, Kempke 1991, S. 144 f., Abb. 26.2; Theune-Großkopf 1992, S. 84; Goßler 1998, S. 517, 644. 

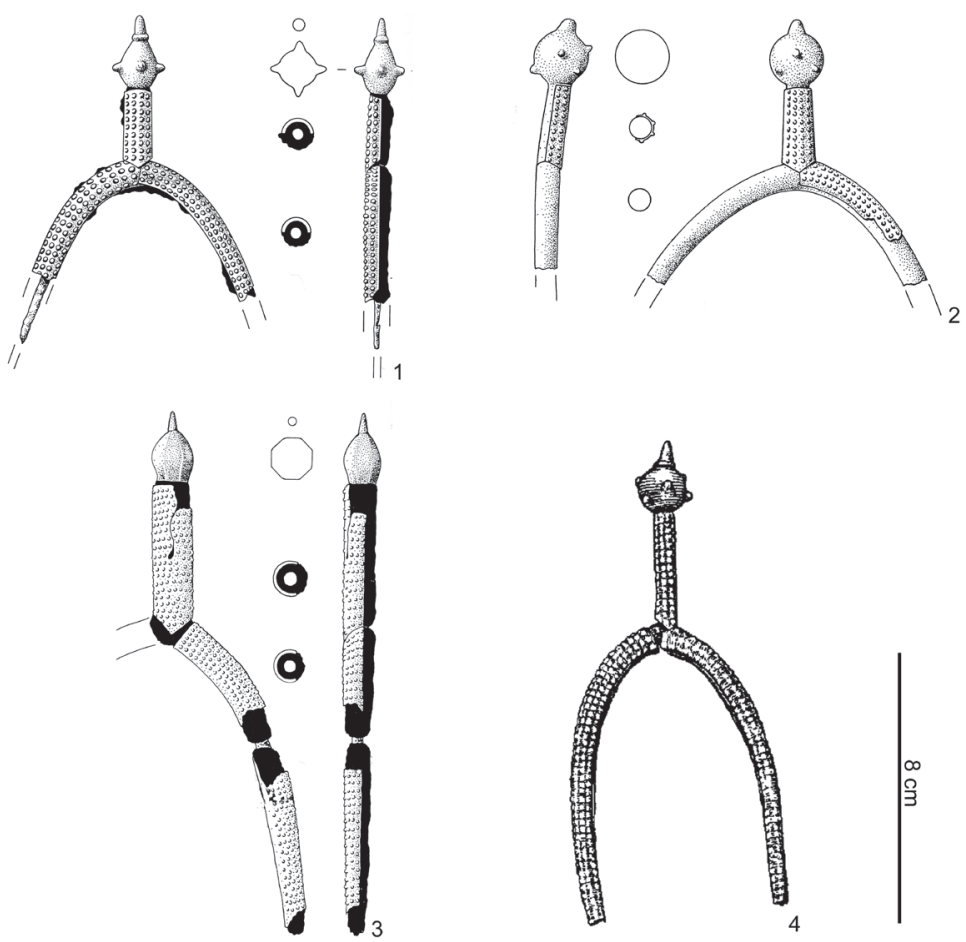

Abb. 10. Kugelstachelsporen mit Buntmetallverkleidung aus Oldenburg (1), Warder (2), Schleswig-Holstein ohne sicheren Fundort (3) und Hamburg (4). Die Zeichnung des Hamburger Sporn ist in der Größe den anderen angenähert (nach Gabriel 1984, S. 140, 144, Abb. 42, 46; Goßler 1998, Taf. 5)

sind (Abb. 10.2). Im Unterschied zu den beiden beschriebenen Exemplaren ist die gegossene Buntmetallkugel mit sechs im mittleren und unteren Bereich versetzt zueinander angeordneten Knubben versehen, und auch die Dornspitze ist eher warzen- als stachelförmig ausgeprägt ${ }^{8}$. Überdies ist die Dornstange (anders als bei allen anderen Stücken) leicht abgewinkelt, was eine Zuordnung zur Variante II.2 nach Z. Hilczerówna (1956, S. 38 ff., Taf. IV) nahelegt (vgl. Gabriel 1984, S. 129).

Weiterhin zu nennen ist ein sehr aufwändig mit vergoldetem Messingblech verkleideter Kugelstachelsporn, der an der Großen Reichenstraße in Hamburg ausgegraben wurde (Abb. 10.4; 11). Das gut erhaltene Objekt weist an der Kugel wieder versetzt unten und mittig angeordnete Noppen auf. Die Blechverkleidung - erneut

${ }^{8}$ Gabriel 1984, S. 129 f., 144, 153, Abb. 46.35; Theune-Großkopf 1992, S. 84; Goßler 1998, S. 517,644 . 


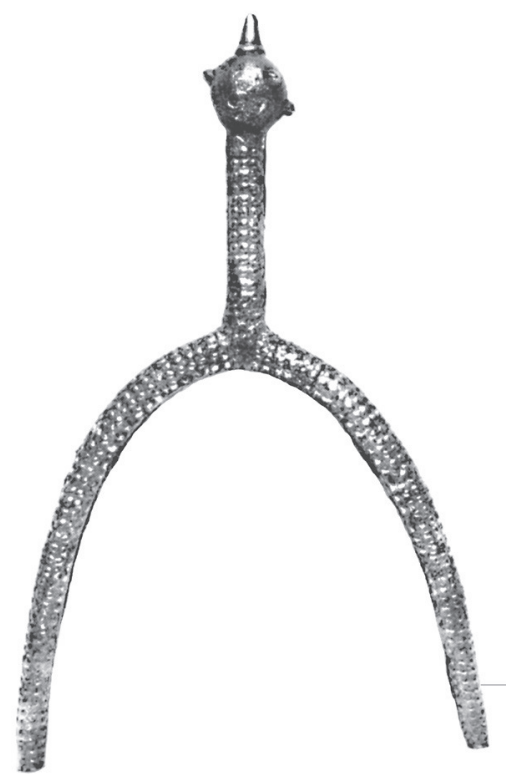

Abb. 11. Der Hamburger Sporn, ohne Maßstab (nach Först 2014, Abbildung auf S. 114)

mit Reihen rundlich erscheinender Buckel - ummantelt Bügel und Stange ${ }^{9}$. Laut E. Först (2014, S. 114) sind die Buckel mit einer Punze von der Unterseite her eingeschlagen worden, doch gerade bei den hier vorliegenden, relativ großen Aufwölbungen ist die Pressung über einem Model wahrscheinlicher. Die Autorin vermutet außerdem ehemals vorhandene Nietplatten, was zutreffen mag. Der Sporn entstammt einer Mistschicht, die von den Ausgräbern der 1950er Jahre nach den keramischen Beifunden zwischen 1125 und 1175 datiert worden war. Da sich unter der Keramik aber importierte Pingsdorfer und glasierte Andenne-Ware sowie anscheinend auch Faststeinzeug befanden, mit der Fundschicht zudem das Gelände „im Zuge der um 1200 planmäßig durchgeführten Baulandgewinnung künstlich aufgehöht wurde", ist eine Datierung in die zweite Hälfte des 12. Jahrhunderts bis um oder bald nach 1200 angezeigt (Gabriel 1984, S. 129; Först 2014, S. 114 [Zitat]).

Des Weiteren gibt es in der ehemaligen Kieler Sammlung vorgeschichtlicher Altertümer, die sich heute in Schleswig befindet, einen Sporn dieser Art, dessen Fundort nicht bekannt ist; vermutlich stammt er aber aus Schleswig-Holstein oder

9 Steffens 1953/55, S. 109 f., Abb. 1.5; Schindler 1957, Taf. 36.1; Gabriel 1984, S. 129; Schneider 1989, S. 21 f., Abb. 12; Theune-Großkopf 1992, S. 84 f., Abb. 14.18; Goßler 1998, S. 517, 644, Taf. 5; Först 2014, S. 114; wiederholt wird von Goldblech gesprochen, doch handelt es sich offensichtlich um eine Vergoldung auf Buntmetall. 


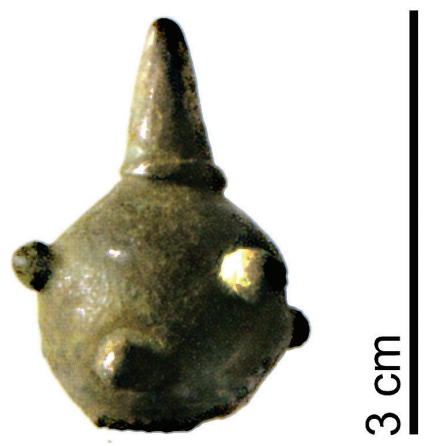

Abb. 12. Kugelstachel von Peckatel (nach Darjes/Ulrich 2011, S. 107, Abb. 1)

dessen Nachbargebieten. Er ist etwas anders gestaltet (Abb. 10.3): Das mit $15 \mathrm{~cm}$ Höhe recht große Stück ist wie die anderen Exemplare aus Eisen, am Bügel und an der überlangen Dornstange mit Buntmetall-Perlpunzblechen dekoriert, doch ist der kupferne Kugelstachel nicht ballig und warzenbesetzt, sondern bei länglicher Grundform achtkantig facettiert, und als Spitze ragt der verjüngte eiserne Dornkörper durch die kupferne Verdickung hindurch ${ }^{10}$.

$\mathrm{Zu}$ diesen vier altbekannten Sporen kommt nach Kenntnis des Verfassers - abgesehen vom Kastavener Exemplar - lediglich ein neuerer Fund: Bei Peckatel (Lkr. Mecklenburg-Strelitz) wurde vor 2011 mithilfe des Metalldetektors der Messing-Kugelstachel eines weiteren derartigen Sporns gefunden. Die Kugel weist zweireihig versetzte Knubben und einen lang ausgezogenen Dorn auf, der mit ringartiger Profilierung von der $1,8 \mathrm{~cm}$ breiten Kugel abgesetzt ist (Abb. 12). Er entstammt einer offenen Siedlung, die zahlreiche spätslawische und wenige frühdeutsche Funde des 11. bis 12./frühen 13. Jahrhunderts erbracht hat - ein Vorläufer des spätmittelalterlichen, später wüsten Dorfes Brustorf. Die Autoren erwägen vorsichtig eine Verbindung des Stücks mit dem slawischen (Namens-) Patron der Ansiedlung (Darjes/Ulrich 2011, S. 106 ff., Abb. 1m).

\section{DATIERUNG UND DEUTUNG}

Mit diesen sechs Exemplaren scheint sich die Sporengruppe derzeit zu erschöpfen. N. Goßler (1998, S. 517) nennt zwei Reitutensilien eher allgemeiner Ähnlichkeit aus England, ansonsten sind sie auf den norddeutschen Raum nördlich und östlich der Elbe beschränkt. Die Funde von Kastaven und Peckatel bilden bereits

\footnotetext{
${ }^{10}$ Gabriel 1984, S. 129 f., 144, 154, Abb. 46.39; ferner Müller-Wille 1977, S. 51, Anm. 43; Theune-Großkopf 1992, S. 84; Goßler 1998, S. 517, 644.
} 
eine erhebliche Osterweiterung des zuvor bekannten Verbreitungsgebietes. I. Gabriel (1984, S. 129) hat diese Sporen als typologische Einheit herausgestellt und erstmals eingehend besprochen, aber die „Sondergruppe“ (Goßler 1998, S. 517) hat auch später verschiedentlich Aufmerksamkeit erfahren. Dabei ging es um Fragen der Herkunft, typologischen Ableitung und Datierung.

„Bei allen Unterschieden im Detail“, so stellte I. Gabriel dar, „,ist die aufwendige Ausführung dieser Prachtsporen doch so gleichartig, dass man sie nur als handwerkliche Erzeugnisse derselben Werkstatt auffassen kann“. Die Perlpunzverzierung lasse „an eine enge Verbindung zu den entsprechend gefertigten slawischen Blecharbeiten denken“, so dass es sich „um Prachtsporen eventuell slawischer Produktion" handeln könne (Gabriel 1984, S. 129). Tatsächlich sind Finger- und Hohlschläfenringe, Messerscheidenbeschläge, Klapperbleche u. a. aus punz-, ziselier- sowie pressmodelverziertem Buntmetallblech typische spätslawische Erzeugnisse (vgl. z. B. Biermann 2009, S. 54-57, 60 ff.), und auch die Gusstechnik war bei den polabischen Slawen hoch entwickelt (vgl. z. B. Schmidt 1994). Zwar ist Vergoldung bei den nordwestslawischen Produkten des 11./12. Jahrhunderts selten, ebenso wie die regelmäßig angelegte, flächendeckende Buckelzier, aber immerhin könnte die Verzierung in dieser Tradition stehen; dem entspräche auch die regionale Verbreitung der Funde im slawisch-deutschen Kontaktraum nördlich und nordöstlich der Elbe. Die vergleichsweise enge räumliche Begrenzung und geringe Frequenz der Funde könnten zugleich die vermutete Werkstattgleichheit untermauern, die durchaus zur Distribution eines Erzeugungsortes und zum Aktionsradius seiner Abnehmer passt. Dagegen lassen sich mit B. Theune-Großkopf (1992, S. 84) die im Detail doch beträchtlichen typologischen Unterschiede der bekannten Ausfertigungen anführen, zudem die möglicherweise divergierende Verzierungstechnik: Während der Hamburger und der Kastavener Sporn von Pressmodeltechnik künden, erscheinen die feineren Buckel der anderen Stücke eher als Punzierungen. Mithin ist eine gemeinsame Herkunft der Sporen denkbar, aber derzeit nicht zu sichern; gewiss ist nur, dass sie sich südwestlich der Ostsee zeitweise einer gewissen Beliebtheit erfreuten.

I. Gabriel (1984, S. 129) datierte die Prunksporen im Schwerpunkt in die zweite Hälfte des 12. Jahrhunderts, K. W. Struve $(1985,178)$ den Oldenburger Sporn in die Mitte desselben Säkulums. B. Theune-Großkopf (1992, S. 84) wollte die Variante sogar schon in die erste Hälfte des 12. Jahrhunderts setzen, und zwar aufgrund ihrer geraden Bügel sowie ihrer Ähnlichkeit mit den vergoldeten Sporen aus dem Grab Kaiser Heinrichs V. von 1125 im Dom zu Speyer (Abb. 13) ${ }^{11}$. Die kaiserlichen Prunksporen seien Vorbild der hier besprochenen Funde, und es stelle sich die Frage, ,warum in der Mitte und zweiten Hälfte des 12. Jhs., in einer Zeit,

11 Vgl. Koch 1982, S. 74 f., Abb. 12; Schulze-Dörrlamm 1992, S. 295 f.; Goßler 1998, Kat.-Nr. 176; Kaufmann 2011, 52; hinsichtlich dieser Sporen herrscht eine gewisse Verwirrung, da es bei der Öffnung der Gräber im Speyerer Dom möglicherweise zu einer Verwechslung mit einem Sporenpaar aus dem Grab Philipps von Schwaben († 1208) kam. 

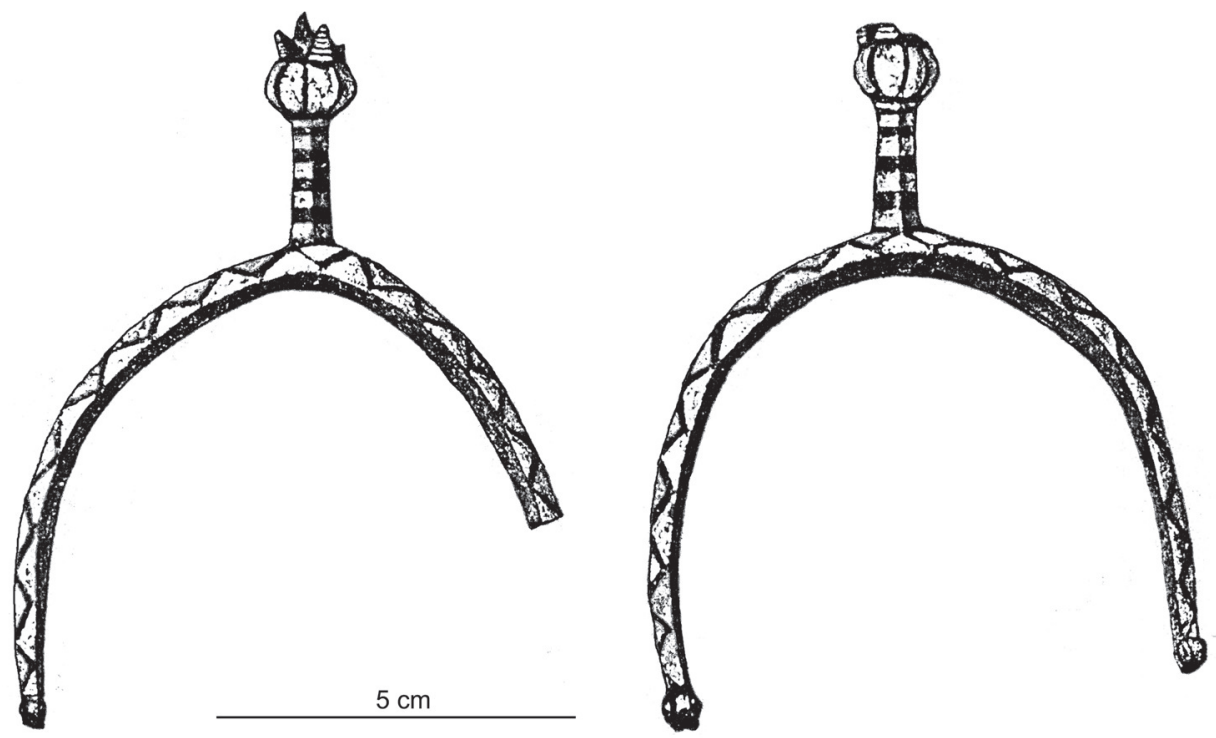

Abb. 13. Feuervergoldete Eisensporen aus dem Grab Kaiser Heinrichs V. im Speyerer Dom (nach Koch 1982, S. 74 Abb. 12)

in der sich der Sporn mit geschweiftem Bügel schon lange durchgesetzt hatte, ausgerechnet für die am kostbarsten ausgestalteten Sporen auf einen veralteten Sporentyp zurückgegriffen worden sein sollte“ (Theune-Großkopf 1984, S. 84). Dem hat wiederum N. Goßler (1998, S. 517) widersprochen - die meisten Sporen jener Epoche würden zwar tatsächlich gebogene Bügel aufweisen, doch gebe es noch etliche Beispiele für gerade Ausführungen. Wegen der Fundzusammenhänge von Warder und Hamburg wies der Forscher die blechverkleideten Sporen in die zweite Hälfte des 12. Jahrhunderts und das frühe 13. Jahrhundert.

Dieser Zeitansatz, nahegelegt auch vom Oldenburger Sporn, wird durch den Neufund von Kastaven unterstrichen, zugleich dessen später Abschnitt betont. Natürlich ist der Detektorfund ohne nähere Stratifizierung für Datierungsfragen wenig belastbar; direkt beim Kirchhof mitten in der Wüstung gehoben, ist die Wahrscheinlichkeit seiner Verbindung mit der Frühphase von Kastaven, näherhin mit dem vermutlich hölzernen ersten Gotteshaus, allerdings größer als seine vordorfzeitliche Ablagerung, etwa als Verlust bei einer Jagd im noch nicht gerodeten Wald. Nach allgemeinen Erwägungen zum ostsiedlungszeitlichen Landesausbau im Lychener Raum und den vorliegenden Lesefunden - eine eventuell slawische Scherbe, sonst nur frühdeutsche Keramik - dürfte das Dorf ohne slawischen Vorgänger erst nach 1200 gegründet worden sein, und entsprechend wurde der Sporn nicht vor dem frühen 13. Jahrhundert verloren. 
Alle bislang vorliegenden Datierungsindizien sprechen dafür, diese Spornvariante mit N. Goßler im Wesentlichen in die letzten Jahrzehnte des 12. Jahrhunderts und das früheste 13. Jahrhundert zu setzen. Der u. a. von I. Gabriel (1984, 129 f.) und B. Theune-Großkopf (1992, S. 84 f.) vertretene Bezug unserer Sporen auf salierzeitliche Prunkausfertigungen ist damit zwar nicht ausgeschlossen - es erscheint plausibel, dass herausragende Elemente hochadelig-höfischer Kultur eine längerfristige Vorbildwirkung entfalten und für Jahrzehnte stilbildend wirken konnten. Gegen eine zu enge Verbindung der hier besprochenen Gruppe mit den Sporen aus dem Grab Heinrichs V. sprechen freilich die trotz der vergleichbaren Gesamtform ganz erheblichen technisch-formalen Abweichungen (Abb. 13): Die kaiserlichen Ausstattungselemente sind aus feuervergoldetem Eisen, aber ohne Buntmetallummantelung, ihre Dornverdickung ist weniger kugel- als mehr zwiebelförmig, statt Warzen haben sie vier kronenförmig angeordnete, kurze Dornspitzen, und anstelle von Perlpunzen zeigen die Kaisersporen ein eingeprägtes Zickzackband (vgl. Koch 1982, S. 74 Abb. 12; Kaufmann 2011, 52 Abb. 29). Weder die technische noch die formale Ähnlichkeit ist frappant. Eher könnten die Kugelwarzen des Kastavener Sporns und seiner Gruppe auf Messing- oder Eisennoppen Bezug nehmen, die die rundlich-doppelpyramidenförmigen Dornverdickungen mehrerer Sporen des 11. Jahrhunderts oder der Zeit um 1100 schmücken, so von Basel und Bissendorf bei Osnabrück (Koch 1982, S. 78, Abb. 17; Weiss 2011, S. 213, Abb. 129; Lau 2014, S. 123 ff., Abb. 8).

\section{DER KULTURHISTORISCHE KONTEXT DES KASTAVEN-FUNDES}

Wir haben es mit Sporen zu tun, die eine sozial hervorgehobene, elitäre Stellung markierten. Wie kommt solche Reitausrüstung, deren Gegenstücke gewöhnlich nur von Burgen (Oldenburg, Warder) oder aus dem frühurbanen Milieu Hamburgs stammen, zur Ostsiedlungszeit in kleine Dörfer des nordwestslawischen Raums, namentlich nach Kastaven? Funde von Reitersporen sind in den nordostdeutschen Dörfern generell nicht allzu selten, auch nicht aus deutlich bäuerlichen Kontexten, denn sie wurden offensichtlich von wohlhabenden Bauern getragen (Goßler 2005; Biermann 2010, S. 222, 270 f., mit weiterer Literatur). Die meisten Sporen, die die Dorf- und Wüstungsforschungen der letzten Jahre ans Tageslicht befördern, sind allerdings erst ins fortgeschrittene 13. Jahrhundert und in die erste Hälfte des 14. Jahrhunderts zu setzen, als die bäuerliche Wirtschaft, am Vorabend der spätmittelalterlichen Agrarkrise, hohe Konjunktur erlebte. Unser Sporn gehört jedoch nicht in diese ländlichen Blütezeiten, sondern in die harte Anfangsphase einer Ansiedlung, in der noch kein Bauer Möglichkeit und Anlass hatte, seinen Wohlstand mit Pferd und Sporen zu demonstrieren.

Den Sporn von Kastaven dürfen wir aufgrund seiner prunkhaften Ausgestaltung sicherlich einem adeligen Träger zuordnen. In Anbetracht dieses Umstands und der 
Datierung des Stücks in die Dorfgründungsphase können wir ihn mithin als ein Zeugnis grundherrschaftlicher Organisation des Landesausbaus interpretieren diesen Sporn wird ein Adeliger verloren haben, der die Gründung des Dorfes veranlasste und beaufsichtigte, anderweitig am Landesausbau beteiligt war oder hier frühzeitig Herrschaft ausübte; ähnlich deutete N. Goßler einen Kugelstachelsporn der Zeit um 1200 aus der Dorfwüstung Göritz bei Rädel (Zauche in Mittelbrandenburg), der dem nicht unbedingt adeligen Lokator - dem örtlichen Organisator der Siedlungsgründung - gehört haben könnte: Der Lokator sei Vertreter einer „führenden Gruppe innerhalb der Dorfbevölkerung“ gewesen, „die bewaffnet war [...], über Reitpferde verfügte" und "schon in der Heimat der Neuansiedler eine führende Stellung inne gehabt" habe. Entsprechende Überlegungen stellte er für einen Kugelstachelsporn des 13. Jahrhunderts aus der Dorfwüstung Helwichsdorf in Berlin-Hellersdorf an (Goßler 2005, S. 146 f.). Ein solcher Kontext erscheint auch für den Kastaven-Sporn plausibel.

Ob sein Träger aus slawischer oder deutscher Familie kam, lässt sich schwer erhellen, denn der in den ostelbischen Landesausbau involvierte Ministerialadel mag sich sowohl aus dem Westen als auch aus einheimischen Eliten rekrutiert haben. Es ist auch ungewiss, ob die geringe Distanz der beiden östlichen Fundorte zueinander (gut $35 \mathrm{~km}$ ) dem Zufall geschuldet ist oder einen zweiten Verbreitungsschwerpunkt dieses Sporentyps mit kulturhistorischer Relevanz anzeigt. Überdies bleibt offen, ob der typologische Bezug des Kastaven-Sporns nach Schleswig-Holstein lediglich allgemeine Stilkontakte ausdrückt, eine besondere Affinität der Eliten im abodritisch-mecklenburgischen Raum zu diesem Sporentyp anzeigt oder mit der Zuwanderung seines Trägers aus dem Nordwesten zusammenhängt, etwa im Zuge der deutschen Ostsiedlung. Zu diesen großen Fragen kann der Sporn keinen Aufschluss gewähren, zumal er als Detektorfund einen ungesicherten Fundkontext besitzt. Insgesamt jedoch erweist sich die kleine Gruppe prächtiger Reiterausstattung als ein beredtes Zeugnis der Transformationen, die das slawisch-deutsche Kontaktgebiet südwestlich der Ostsee im späten 12. und frühen 13. Jahrhundert erlebte.

\section{BIBLIOGRAPHIE}

Agthe M. 2017, Kirchen zwischen mittlerer Elbe und Bober. Untersuchungen zu Aspekten der archäologischen Denkmalpflege und Baugeschichte. Forschungen zur Archäologie im Land Brandenburg 17, Wünsdorf.

Bergstedt C. 2002, Kirchliche Siedlung des 13. Jahrhunderts im brandenburgisch-mecklenburgischen Grenzgebiet, Studien zur Geschichte, Kunst und Kultur der Zisterzienser 15, Berlin.

Biermann F. 2009, Brandgrab-Bootsgrab-Kammergrab. Die slawischen Gräberfelder von Usedom im Kontext der früh- und hochmittelalterlichen Bestattungssitten in Mecklenburg und Pommern. Archäologie und Geschichte im Ostseeraum 7, Rahden/Westfalen.

- 2010, Archäologische Studien zum Dorf der Ostsiedlungszeit. Die Wüstungen Miltendorf und Damsdorf in Brandenburg und das ländliche Siedlungswesen des 12. bis 15. Jahrhunderts in Ostmitteleuropa, Forschungen zur Archäologie im Land Brandenburg 12, Wünsdorf. 
- 2017, Neue Wege der Burgwallforschung. Metalldetektorprospektionen auf Brandenburgs slawischen Befestigungen, „Archäologie in Berlin und Brandenburg“ 2015 (2017), S. 91-93.

Biermann F./Kersting Th.

- 2017, Archäologie der Slawenzeit - 25 Jahre nach der Wende, in: M. Meyer, F. Schopper, M. Wemhoff (Hrsg.), Feuerstein - Fibel - Fluchttunnel. Archäologie in Berlin und Brandenburg seit der Wende, Petersberg, S. 101-120.

Darjes E., Ulrich J. 2011, Alt Brustorf, Lkr. Mecklenburg-Strelitz - Die Rekonstruktion einer dörflichen Siedlung und Gemarkung anhand von archäologischen und historischen Quellen, „Archäologische Berichte aus Mecklenburg-Vorpommern“18, S. 106-117.

Enders L. 1986, Historisches Ortslexikon für Brandenburg VIII: Uckermark, Veröffentlichungen des Staatsarchivs Potsdam 21, Weimar.

- 1992, Die Uckermark. Geschichte einer kurmärkischen Landschaft vom 12. bis zum 18. Jahrhundert, Veröffentlichungen des Brandenburgischen Landeshauptarchivs Potsdam 28, Weimar.

- 2003, Die wüsten Kirchen auf den Feldmarkgrenzen - Zur Geschichte von Wittstock, Kröchlendorf und Fahrenholz sowie von Bischofshagen und Blankensee, in: W. Blaschke, R. Schmook (Hrsg.), Beiträge zur Uckermärkischen Kirchengeschichte. 12 ausgewählte Aufsätze aus den Jahren 1979 bis 1989, Neuenhagen, S. 121-135.

Först E. 2014, Im Mist gefunden - Der vergoldete Reitersporn von der Reichenstraßeninsel, in: R.-M. Weiss, A. Klammt (Hrsg.), Mythos Hammaburg. Archäologische Entdeckungen zu den Anfängen Hamburgs. Veröffentlichungen des Helms-Museums, Archäologisches Museum Hamburg 107, Hamburg, S. 114.

Gabriel I. 1984, Starigard/Oldenburg, Hauptburg der Slawen in Wagrien I, Stratigraphie und Chronologie, Offa-Bücher 52, Neumünster.

Gabriel I., Kempke T. 1991, Ausgrabungsmethode und Chronologie, in: M. Müller-Wille (Hrsg.), Starigard/Oldenburg. Ein slawischer Herrschersitz des frühen Mittelalters in Ostholstein, Neumünster, S. 123-147.

Goßler N. 1998, Untersuchungen zur Formenkunde und Chronologie mittelalterlicher Stachelsporen in Deutschland (10.-14. Jahrhundert), ,Berichte der RGK“ 79, S. 479-662.

- 2005, Gedanken zur sozialen Schichtung im Dorf des Mittelalters aus archäologischer Sicht, in: C. Dobiat (Hrsg.), Reliquiae Gentium I, Rahden/Westfalen, S. 141-154.

Greule A. 2014, Deutsches Gewässernamenbuch: Etymologie der Gewässernamen und der zugehörigen Gebiets-, Siedlungs- und Flurnamen, Berlin/Boston.

Heinrich G. 1995, (Hrsg.), Berlin und Brandenburg. Handbuch der historischen Stätten Deutschlands 10 , Stuttgart.

Herrmann J. 1968, Siedlung, Wirtschaft und gesellschaftliche Verhältnisse der slawischen Stämme zwischen Oder/Neiße und Elbe. Studien auf der Grundlage archäologischen Materials. Deutsche Akademie der Wissenschaften zu Berlin. Schriften der Sektion für Vor- und Frühgeschichte 23, Berlin.

Hilczerówna Z. 1956, Ostrogi Polskie z X-XIII wieku, Poznań.

Jerchel H. 1937, (Bearb.), Die Kunstdenkmäler des Kreises Templin, Berlin.

Kaufmann S. 2011, Sporen aus dem Grab Heinrichs V., in: Die Salier. Macht im Wandel. Ausstellungskatalog, Speyer, S. 52.

Kersting Th. 2015, „Citizen Science“ und Landesarchäologie: erfolgreiche Partnerschaft in Brandenburg, „Forum Kritische Archäologie“ 4, S. 62-64.

- 2016, Zwischen Krieg und Frieden. Waldlager der Roten Armee in Brandenburg. Begleitheft zur Sonderausstellung im Archäologischen Landesmuseum Brandenburg, Wünsdorf.

Kersting Th., Petzel M. 2015, Metalldetektorgänger - Helfer oder Konkurrenten der Landesarchäologie, „Archäologie in Berlin und Brandenburg“ 2013 (2015), S. 17-20.

Koch R. 1982, Stachelsporen des frühen und hohen Mittelalters, „Zeitschrift für Archäologie des Mittelalters" 10 , S. 63-83.

Lange M. 2010, Himmelpfort, in: H.-D. Heimann, K. Neitmann, W. Schich u. a. (Hrsg.), Brandenburgisches Klosterbuch. Handbuch der Klöster, Stifte und Kommenden bis zur Mitte des 16. Jahrhunderts 1. Brandenburger Historische Studien 14, Berlin, S. 612-624.

Lau D. 2014, Ein salierzeitlicher Rittersitz in Bissendorf, Gde. Bissendorf, Lkr. Osnabrück, „Nachrichten aus Niedersachsens Urgeschichte" 83, S. 115-131. 
Lisch G.C.F. 1844, Geschichte der Johanniter-Comthureien Nemerow und Gardow, in: „Jahrbücher des Vereins für Mecklenburgische Geschichte und Altertumskunde“" 9, S. 28-96.

Marschalleck K.-H. 1937, Vor- und frühgeschichtlicher Überblick, in: H. Jerchel u. a. (Bearb.), Die Kunstdenkmäler des Kreises Templin, Berlin, S. 9-17.

Müller-Wille M. 1977, Krieger und Reiter im Spiegel früh- und hochmittelalterlicher Funde Schleswig -Holsteins, „Offa“ 34, S. 40-74.

Schindler R. 1957, Ausgrabungen in Alt Hamburg. Neue Ergebnisse zur Frühgeschichte der Hansestadt, Hamburg.

Schmidt R. 1930, Das Geheimnis der ,Wüsten Kirchen “ im Kreise Templin, Berkenlatten - Brüsenwalde - Krewitz - Kröchlendorf - Milmersdorf - Retzow - Sähle, „Templiner Kreiskalender“ 1930, S. 17-27.

- 1937, Reise durch das Amt Badingen, „Templiner Kreiskalender“ 1937, S. 19-32.

Schmidt V. 1994, Die Gußtechnik im Schmuckhandwerk bei den Westslawen, „Zeitschrift für Archäologie 28, S. 107-121.

Schneider R. 1989, Ergebnisse hamburgischer Bodendenkmalpflege nördlich der Elbe, in: R. Busch (Hrsg.), Bodendenkmalpflege in Hamburg. Veröffentlichungen des Hamburger Museums für Archäologie und die Geschichte Hamburgs 56, Neumünster, S. 11-26.

Schulze-Dörrlamm M. 1992, Grabbeigaben Kaiser Heinrichs IV. (1056-1106) und Kaiser Heinrichs V. (1106-1125), in: Das Reich der Salier 1024-1125. Ausstellungskatalog, Sigmaringen, S. 295-296.

Sorg W. 1936, Wüstungen in den brandenburgischen Kreisen Ruppin und Templin und deren Ursachen, Berlin.

Steffens H.-G. 1953/55, Die Ausgrabungen in der Großen Reichenstraße zu Hamburg (1953-1954), „Hammaburg“ 4, S. 105-118.

Struve K.W. 1981, Die Burgen in Schleswig-Holstein 1: Die slawischen Burgen, Offa-Bücher 35, Neumünster.

- 1985, Starigard - Oldenburg. Geschichte und archäologische Erforschung der slawischen Fürstenburg in Wagrien, in: 750 Jahre Stadtrecht Oldenburg in Holstein, Oldenburg, S. 73-206.

Theune-Großkopf B. 1992, Sporen, in: Das Reich der Salier 1024-1125. Ausstellungskatalog, Sigmaringen, S. 82-86.

Weiss C. 2011, Vier Reitersporen, in: Die Salier. Macht im Wandel. Ausstellungskatalog, Speyer, S. 213. 